\title{
A homogenized model for size-effects in porous metals
}

\section{Niordson, Christian F.; Tvergaard, Viggo}

Published in:

Journal of the Mechanics and Physics of Solids

Link to article, DOI:

10.1016/j.jmps.2018.09.004

Publication date:

2019

Document Version

Peer reviewed version

Link back to DTU Orbit

Citation (APA):

Niordson, C. F., \& Tvergaard, V. (2019). A homogenized model for size-effects in porous metals. Journal of the Mechanics and Physics of Solids, 123, 222-233. https://doi.org/10.1016/j.jmps.2018.09.004

\section{General rights}

Copyright and moral rights for the publications made accessible in the public portal are retained by the authors and/or other copyright owners and it is a condition of accessing publications that users recognise and abide by the legal requirements associated with these rights.

- Users may download and print one copy of any publication from the public portal for the purpose of private study or research.

- You may not further distribute the material or use it for any profit-making activity or commercial gain

- You may freely distribute the URL identifying the publication in the public portal

If you believe that this document breaches copyright please contact us providing details, and we will remove access to the work immediately and investigate your claim 


\section{Accepted Manuscript}

A homogenized model for size-effects in porous metals

Christian F. Niordson, Viggo Tvergaard

PII:

S0022-5096(18)30602-1

DOI: https://doi.org/10.1016/j.jmps.2018.09.004

Reference: MPS 3435

To appear in:

Journal of the Mechanics and Physics of Solids

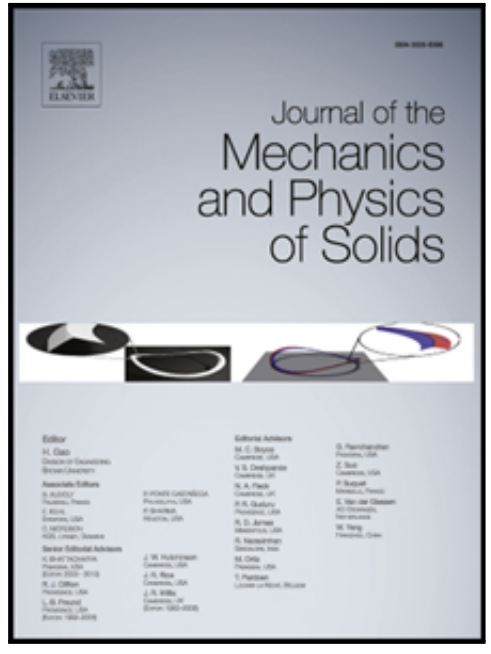

Received date: $\quad 9$ July 2018

Revised date: $\quad 4$ September 2018

Accepted date: $\quad 5$ September 2018

Please cite this article as: Christian F. Niordson, Viggo Tvergaard, A homogenized model for size-effects in porous metals, Journal of the Mechanics and Physics of Solids (2018), doi: https://doi.org/10.1016/j.jmps.2018.09.004

This is a PDF file of an unedited manuscript that has been accepted for publication. As a service to our customers we are providing this early version of the manuscript. The manuscript will undergo copyediting, typesetting, and review of the resulting proof before it is published in its final form. Please note that during the production process errors may be discovered which could affect the content, and all legal disclaimers that apply to the journal pertain. 


\title{
A homogenized model for size-effects in porous metals
}

\author{
Christian F. Niordson and Viggo Tvergaard \\ Department of Mechanical Engineering, Technical University of Denmark, \\ Nils Koppels Allé, Building 404, DK-2800 Kgs. Lyngby
}

\begin{abstract}
A simple method for enriching conventional homogenized porous plasticity models with size-dependence for micron scale voids is proposed. A recent strain gradient plasticity theory with dissipative gradient effects is generalized to finite strains in order to quantify size-scale effects on void growth under different loading conditions. Based on numerical cell model studies for regularly distributed voids, the size-dependence of homogenized yield surfaces is quantified in terms of effective stress and mean stress. It is proposed to account for void size effects by two simple extensions to conventional models. One is the establishment of a new size-dependent effective void volume fraction smaller than the physical one. The other is the introduction of a size-dependent reduction of the influence of the mean stress. The results obtained are based on numerical unit cell calculations, but it is conjectured that they may be used for any isotropic yield surface for porous metals that includes explicit dependence on porosity and mean stress.
\end{abstract}

Keywords:

\section{Introduction}

The influence of small voids on ductile fracture has been investigated by many authors. Early on McClintock (1968) and Rice and Tracey (1969) have analyzed the growth of a single void in an infinite ductile solid. Subsequently, a model for the behavior of a porous solid with a given volume fraction of voids was developed by Gurson (1977). The developments in this field are well described in a number of reviews (Garrison and Moody, 1987; Tvergaard, 1990; Benzerga and Leblond, 2010; Benzerga et al., 2016). 
When the void radius is sufficiently small, it must be expected that the growth behavior is not well represented by conventional plasticity theory, due to size-effects originating from gradient hardening exhibited by metals on the micron scale. Such size-effects have been observed experimentally in indentation (Stelmashenko et al., 1993; Ma and Clarke, 1995; Swadener et al., 2002), in torsion (Fleck et al., 1994), and in bending (Stölken and Evans, 1998; Haque and Saif, 2003). As the gradient hardening increases for increasing strain gradient and the strain gradients around voids are higher the smaller the void radius, clearly smaller voids will grow more slowly under the same macroscopic stresses. Size dependent void growth has been investigated for single voids under hydrostatic loading (Fleck and Hutchinson, 1997; Huang et al., 2000), while the influence of constitutive length parameters on cavitation instabilities has been studied by Niordson and Tvergaard (2006, 2007). Cell model investigations of size-effects on void growth to coalescence has been carried out for isotropic plasticity by Niordson (2008) and for strain gradient crystal plasticity models by Borg et al. (2008) and Ling et al. (2018).

Some investigations in the literature have been devoted to the development of modified Gurson-type yield surfaces, both accounting for strain gradient effects (e.g. Li et al., 2003; Wen et al., 2005; Monchiet and Bonnet, 2013), and effects of surface energy (e.g. Dormieux and Kondo, 2010; Monchiet and Kondo, 2013). The strength properties of nanoporous materials have been considered (Morin et al., 2015; Brach et al., 2017), using a non-linear homogenization procedure based on a 3-layered description and including surface-stress effects by use of an imperfect-coherent interface model. Furthermore, a representative volume element investigation of size-effects on the yield surface of metals with dilute porosities has been carried out by $\mathrm{Li}$ and Steinmann (2006).

In the present paper yield surfaces for a porous strain-gradient solid are first calculated numerically, using a unit cell model with a spherical void for different combinations of the characteristic material length, the void volume fraction and the void radius. The material is here taken to be non-hardening, represented in terms of a finite strain generalization of the strain-gradient model developed by Gudmundson (2004) which was reformulated mathematically by Fleck and Willis (2009b). In the present study energetic gradient effects are ignored, accounting for dissipative gradient effects only. Also the yield surface for the conventional porous solid with no strain gradient effects is computed numerically based on the cell-model. Then it is proposed that the relevant yield surface for the ductile strain gradient material can be esti- 
mated with good approximation from the conventional yield surface by using two size-dependent parameters, denoted by $Q_{1}$ and $Q_{2}$, that scale the void volume fraction and the mean stress, respectively. The values of these two parameters are computed for a range of values of the characteristic material length, and it will be shown that the values are largely independent of void volume fraction.

\section{Material Model}

The material model used is a visco-plastic finite strain generalization of the strain gradient plasticity by Gudmundson (2004). In the present context energetic gradient effects are neglected, and only dissipative gradient effects are included. The mathematical framework for obtaining the numerical solution method extends the approach developed by Fleck and Willis (2009b) for small strains to finite strains in an updated Lagrangian setting similar to the method proposed by McMeeking and Rice (1975) in a conventional elastic-plastic setting.

In an updated reference frame the total strain rate, $\dot{\varepsilon}_{i j}=\dot{\varepsilon}_{i j}^{e}+\dot{\varepsilon}_{i j}^{p}$, is decomposed into an elastic part, $\dot{\varepsilon}_{i j}^{e}$, and a plastic part, $\dot{\varepsilon}_{i j}^{p}$. The principle of virtual work (see Gudmundson, 2004; Fleck and Willis, 2009a) in Cartesian components is expressed in the deformed configuration as

$$
\int_{V}\left(\sigma_{i j} \delta \dot{\varepsilon}_{i j}+\left(q_{i j}-s_{i j}\right) \delta \dot{\varepsilon}_{i j}^{p}+\tau_{i j k} \delta \dot{\varepsilon}_{i j, k}^{p}\right) d V=\int_{S}\left(T_{i} \delta \dot{u}_{i}+t_{i j} \delta \dot{\varepsilon}_{i j}^{p}\right) d S
$$

Here, $\sigma_{i j}$ is the Cauchy stress tensor, $s_{i j}=\sigma_{i j}-\delta_{i j} \sigma_{k k} / 3$ is the stress deviator, $q_{i j}$ is the micro-stress tensor which is work conjugate to the plastic strain rate, $\dot{\varepsilon}_{i j}^{p}$, and $\tau_{i j k}$ is the higher order stress which is work conjugate to the plastic strain rate gradient, $\dot{\varepsilon}_{i j, k}^{p}$. Denoting the outward unit normal to the surface $S$ by $n_{i}$, the right hand side of the principle of virtual work includes the conventional traction vector $T_{i}=\sigma_{i j} n_{j}$ and the higher order traction $t_{i j}=\tau_{i j k} n_{k}$, which are work conjugates to the boundary displacement rate and plastic strain rate, respectively.

The strong form of (1) is given by (see also Gudmundson, 2004)

$$
\begin{aligned}
& \sigma_{i j, j}=0 \\
& q_{i j}-s_{i j}-\tau_{i j k, k}=0
\end{aligned}
$$

in the volume, $V$, where the first set of equations is recognized as the conventional equilibrium equations in the absence of body forces, and the second set of equations constitutes the higher order equilibrium equations. 
Following Fleck and Hutchinson (2001) and Gudmundson (2004), an effective plastic strain rate is defined based on the plastic strain rate and its gradient according to

$$
\left(\dot{E}^{p}\right)^{2}=\frac{2}{3} \dot{\varepsilon}_{i j}^{p} \dot{\varepsilon}_{i j}^{p}+L_{D}^{2} \dot{\varepsilon}_{i j, k}^{p} \dot{\varepsilon}_{i j, k}^{p}
$$

where $L_{D}$ is a dissipative constitutive length parameter. A visco-plastic potential is defined as

$$
\Phi\left[\dot{E}^{p}, E^{p}\right]=\int_{0}^{\dot{E}^{p}} \sigma_{c}\left[\dot{E}^{p \prime}, E^{p}\right] \mathrm{d} \dot{E}^{p \prime} .
$$

from which the dissipative stress quantities defined upon investigation of the variation of the potential (see Fleck and Willis, 2009b)

$$
\delta \Phi=q_{i j} \delta \dot{\varepsilon}_{i j}^{p}+\tau_{i j k} \delta \dot{\varepsilon}_{i j, k}^{p}
$$

This results in the following relations for the micro-stress and the higherorder stress, respectively

$$
q_{i j}=\frac{2}{3} \sigma_{c} \frac{\dot{\varepsilon}_{i j}^{p}}{\dot{E}^{p}} \text { and } \tau_{i j k}=L_{D}^{2} \sigma_{c} \frac{\dot{\varepsilon}_{i j, k}^{p}}{\dot{E}^{p}}
$$

Substituting Eq. (7) into Eq. (4), we obtain the effective stress:

$$
\sigma_{c}^{2}=\frac{3}{2} q_{i j} q_{i j}+\frac{1}{L_{D}^{2}} \tau_{i j k} \tau_{i j k}
$$

\section{Solution method and the numerical framework}

The solution is obtained in a staggered approach, in which the plastic strain rate field is obtained based on a known stress-deviator field in the updated Cartesian reference frame. Subsequently, the incremental displacement field is found using a conventional updated Lagrangian Forward Euler time stepping procedure (see McMeeking and Rice, 1975).

The plastic strain rate, $\dot{\varepsilon}_{i j}^{p}$, is found using Minimum Principle I of Fleck and Willis (2009b) as proposed by Niordson and Hutchinson (2011) and Nielsen and Niordson (2014) within a small strain framework. Higher order equilibrium is satisfied by the minimizing field among all kinematically admissible fields, $\dot{\varepsilon}_{i j}^{p *}$, for the functional

$$
H=\inf _{\dot{\varepsilon}_{i j}^{p *}} \int_{V}\left(\Phi\left[\dot{E}^{p *}, E^{p}\right]-s_{i j} \dot{\varepsilon}_{i j}^{p *}\right) d V-\int_{S_{T}} t_{i j} \dot{\varepsilon}_{i j}^{p *} d S
$$


where, $S_{T}$ is the part of the boundary where the higher order traction is prescribed. In the present finite strain framework the minimization is carried out in an updated Cartesian reference frame. Stationarity of the functional $H$ results in the variational statement

$$
\int_{V}\left(q_{i j} \delta \dot{\varepsilon}_{i j}^{p}+\tau_{i j k} \delta \dot{\varepsilon}_{i j, k}^{p}\right) \mathrm{d} V=\int_{V} s_{i j} \delta \dot{\varepsilon}_{i j}^{p} \mathrm{~d} V+\int_{S} t_{i j} \delta \dot{\varepsilon}_{i j}^{p} \mathrm{~d} S
$$

A forward Euler time-stepping algorithm is employed, where for each time increment the plastic strain rate field is obtained iteratively based on the discretized version of Equation (10) as laid out in Nielsen and Niordson (2014). For each time increment, a finite element approximation to the plastic strain rate field is determined based on the stress field in an updated reference configuration.

Upon convergence of the plastic strain rate field, the nodal displacement increments are determined based on the Principle of Virtual Work (1), specialized for $\delta \dot{\varepsilon}_{i j}^{p}=0$ :

$$
\int_{V} \sigma_{i j} \delta \dot{\varepsilon}_{i j} \mathrm{~d} V=\oint_{S} T_{i} \delta \dot{u}_{i} \mathrm{~d} S
$$

The conventional Principle of Virtual Work is rewritten in incremental form in an updated reference frame $\left(V_{0}, S_{0}\right)$ as

$$
\int_{V_{0}} \dot{P}_{i j} \delta \dot{u}_{j, i} d V=\int_{S_{0}} \dot{T}_{i}^{0} \delta \dot{u}_{i} d S
$$

where $P_{i j}$ is the first Piola-Kirchhoff stress and $T_{i}^{0}$ is the nominal traction vector. This forms the basis for the updated Lagrangian finite element method proposed by McMeeking and Rice (1975). Aiming at an elastic constitutive relation which is to be formulated in terms of the Jaumann rate of the Kirchhoff stress ${ }_{\zeta}^{\nabla}$ the incremental Principle of Virtual Work is written as

$$
\int_{V_{0}}\left(\stackrel{\nabla}{\varsigma}_{i j} \delta \dot{\varepsilon}_{i j}-\sigma_{i j}\left(2 \dot{\varepsilon}_{i k} \delta \dot{\varepsilon}_{k j}-\dot{u}_{k, j} \delta \dot{u}_{k, i}\right)\right) d V=\int_{S_{0}} \dot{T}_{i}^{0} \delta \dot{u}_{i} d S
$$

Employing the hypo-elastic constitutive relation $\stackrel{\nabla}{\varsigma}_{i j}=L_{i j k l}\left(\dot{\varepsilon}_{k l}-\dot{\varepsilon}_{k l}^{p}\right)$, where $L_{i j k l}$ is the isotropic elastic stiffness tensor, the incremental Principle of Virtual Work is given by

$$
\int_{V_{0}}\left(L_{i j k l} \dot{\varepsilon}_{k l} \delta \dot{\varepsilon}_{i j}-\sigma_{i j}\left(2 \dot{\varepsilon}_{i k} \delta \dot{\varepsilon}_{k j}-\dot{u}_{k, j} \delta \dot{u}_{k, i}\right)\right) d V=\int_{S_{0}}\left(L_{i j k l} \dot{\varepsilon}_{k l}^{p} \delta \dot{\varepsilon}_{i j}+\dot{T}_{i}^{0} \delta \dot{u}_{i}\right) d S(14)
$$


This serves as a basis for a finite element dicretization where eight node serendipity elements are used to interpolate displacements, and where the plastic strain rate on the right hand side is known from Minimum Principle I above.

A power-law relation for the visco-plastic behavior is assumed according to

$$
\sigma_{c}\left[\dot{E}^{p}, E^{p}\right]=g\left[E^{p}\right]\left(\frac{\dot{E}^{p}}{\dot{\varepsilon}_{0}}\right)^{m}
$$

where $\dot{\varepsilon}_{0}$ is a reference strain rate, $m$ is the visco-plastic exponent and $g\left[E^{p}\right]$ is the hardening function for the material. In the present studies of yield surfaces for porous metals no hardening is assumed such that $g\left[E^{p}\right]=\sigma_{y}$ is the constant yield stress of the matrix material.

\section{Problem Formulation}

A material porosity is modeled by a regular distribution of spherical voids. The voids are assumed to be arranged in planes in a regular hexagonal pattern as shown in Fig. (1a). Fig. (1b) shows three planes of the voids. The hexagonal cell-model shown in Fig. (1a) and (b) is approximated by the axisymmetric cell shown in Fig. (1c). The void plane distance is denoted $2 H_{c}$ and the in plane void distance is denoted $2 R_{c}$. The initial void radius is denoted $R_{v}$. The initial void volume fraction is given by

$$
f_{0}=\frac{2 R_{v}^{3}}{3 R_{c}^{2} H_{c}}
$$

A Rayleigh-Ritz method is employed to ensure that a constant ratio, $\rho$ of transverse to axial stress is maintained for each analysis

$$
\rho=\frac{\sigma_{22}}{\sigma_{11}}
$$

The Rayleigh-Ritz method employs three generalized degrees of freedom, of which $\Delta_{1}$ and $\Delta_{2}$ control the outer dimensions of the cell, and the third is a visco-plastic multiplier.

Due to symmetry the tangential part of the conventional traction vector is enforced to vanish along the boundaries of the cell. Similarly, symmetry demands that $\dot{\varepsilon}_{12}^{p}=0$ along the boundary of the cell, while other plastic strain 


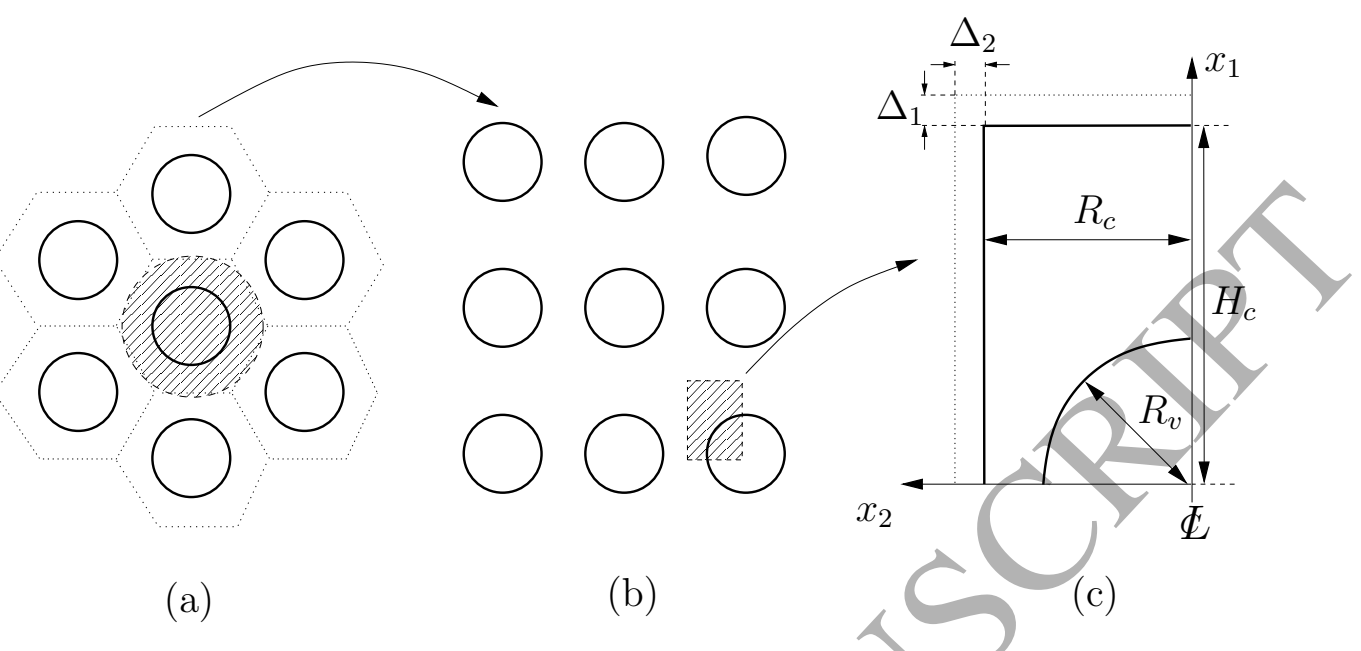

Figure 1: Cell model for a regular array of voids. (a) Hexagonal distribution of voids. The cylindrical cell containing a single void is indicated by the dashed circle. (b) shows the different layers of voids. (c) Using the symmetry of the problem half a void can be modeled in an axisymmetric cell. The cell radius and height are denoted $R_{c}$ and $H_{c}$, respectively, and the void radius is denoted $R_{v}$.

components remain unconstrained. Hence, the boundary conditions applied to the cell are specified by

$$
\begin{array}{llll}
\dot{u}_{1}=0, & \dot{T}_{2}^{0}=0, \dot{\varepsilon}_{12}^{p}=t_{11}=t_{22}=0 & \text { for } & x_{1}=0 \\
\dot{u}_{1}=\dot{\Delta}_{1}, \quad \dot{T}_{2}^{0}=0, \dot{\varepsilon}_{12}^{p}=t_{11}=t_{22}=0 & \text { for } & x_{1}=H_{c}+\Delta_{1} \\
\dot{u}_{2}=0, & \dot{T}_{1}^{0}=0, \dot{\varepsilon}_{12}^{p}=t_{11}=t_{22}=0 & \text { for } & x_{2}=0 \\
\dot{u}_{2}=\dot{\Delta}_{2}, & T_{1}^{0}=0, \dot{\varepsilon}_{12}^{p}=t_{11}=t_{22}=0 & \text { for } & x_{2}=R_{c}+\Delta_{2}
\end{array}
$$

where $\dot{\Delta}_{1}$ and $\dot{\Delta}_{2}$ are determined such that a constant ratio of the average true stresses is maintained.

In addition to the in-plane components of the plastic strain rate gradient tensor, the following non-zero out-of-plane components must be properly accounted for:

$$
\begin{aligned}
& \dot{\varepsilon}_{13,3}^{p}=\dot{\varepsilon}_{31,3}^{p}=\dot{\varepsilon}_{12}^{p} / x_{2} \\
& \dot{\varepsilon}_{23,3}^{p}=\dot{\varepsilon}_{32,3}^{p}=\left(\dot{\varepsilon}_{22}^{p}-\dot{\varepsilon}_{33}^{p}\right) / x_{2}
\end{aligned}
$$

\section{Results}

Numerical solutions will now be presented based on cell model analyses. We investigate a matrix material with yield stress to Young's modulus ratio 
of $\sigma_{y} / E=0.004$, Poisson's ratio $\nu=0.3$, and a reference strain rate of $\dot{\varepsilon}_{0}=0.005 \mathrm{~s}^{-1}$. For the majority of the results presented the visco-plastic exponent is $m=0.01$, except for results in Figure 4, where the influence of $m$ is investigated. Void distributions of equal in plane and out of plane spacing is investigated such that $H_{c}=R_{c}$. The axial loading rate is chosen to be equal to the reference strain rate.

To set the stage for the investigations of size-effects in porous metals conventional response curves and void growth curves are first presented in Figure 2a and Figure 2b, respectively. Response curves show true axial stress as a function of linear axial strain, while void growth curves show the relative void volume fraction as a function of von Mises stress. Results are shown for three different stress ratios, $\rho$, and three different initial void volume fractions $f_{0}$. It may be observed how increasing initial void volume fractions lead to yield at lower applied stress levels, especially for increasing stress ratios. Furthermore, material softening is observed to increase with both the initial void volume fraction as well as increasing stress ratio. Investigation of the void growth curves explains this effect due to significant increase in void volume fractions for increasing stress ratios and initial void volume fractions.

For a stress ratio of $\rho=0.5$, response curves and void growth curves are shown in Figure $3 \mathrm{a}$ and b, respectively. The solid lines show results for conventional materials $\left(L_{D}=0\right)$ for two different void volume fractions, $f_{0}=0.01$ and $f_{0}=0.04$. The smaller void volume fraction exhibits a higher yield point, as well as less softening and void growth compared to the larger void volume fraction. The two dashed curves in the figures show results for the strain gradient plasticity model for size effects in the material with the larger porosity, $f_{0}=0.04$. It is seen that increasing the value of the length parameter normalized by the void radius, $L_{D} / R_{v}$, from 0 to 0.25 and further to the value 0.5 , leads to a size-effect manifesting itself through a delayed yield point and suppressed void growth. Furthermore, it is observed that the response curve and the void growth curve for the size-dependent material with $L_{D} / R_{v}=0.5$ and $f_{0}=0.04$ rather closely resembles that of the conventional material $\left(L_{D}=0\right)$ with the smaller porosity of $f_{0}=0.01$. This suggests that the size-effect in the material response and the porosity growth, may be approximated by those of a conventional material with a smaller void volume fraction.

In order to investigate the effect of size on the homogenized plastic response of porous metals, yield surfaces will be established in the mean stress space, von Mises stress space $\left(\sigma_{m}, \sigma_{e}\right)$. The delay of the yield point on the 
micron scale is quantified based on analyses for a range of $\rho$ values from -0.5 to 1.0 spanning the entire range of positive stress triaxialities. Figure 4 illustrates how the yield point is determined for $f_{0}=0.04, \rho=0.80$ for the conventional material $\left(L_{D}=0\right)$ and two strain gradient plasticity (SGP) cases with the material length parameter $L_{D} / R_{v}=0.20,0.40$. The yield point for the homogenized material model is determined at $0.2 \%$ residual strain. The very flat responses hereafter show that the calculated yield points are insensitive to defining yielding at $0.2 \%$ strain or a slightly larger value. The figure shows how the yield point is delayed as void size decreases relative to the material length parameter $L_{D}$. Results are shown for five values of the visco-plastic exponent, $m=0.005,0.01,0.02,0.04,0.08$, and it is seen that the smaller values of $m$ leads to very similar results for the yield point. In the remaining analyses $m=0.01$ is chosen as a reasonable compromise between numerical efficiency and small rate effects.

Yield surfaces are presented in Figure $5 \mathrm{a}$ and $5 \mathrm{~b}$ for the initial porosities $f_{0}=0.04$ and $f=0.08$, respectively. The yield surfaces are presented in the mean stress, von Mises stress space $\left(\sigma_{m}, \sigma_{e}\right)$. The dotted curves show the yield surfaces as obtained by cell model analyses for conventional materials, and the solid curves show size-dependent yield surfaces as obtained using strain gradient plasticity theory with different length parameters $L_{D} / R_{v}$. It is observed that for smaller void sizes the yield surfaces both shift up along the von Mises stress axis and out along the mean stress axis.

In Figure 5 the dashed lines indicate the boundaries between the regimes of void growth and void coalescence. According to Koplik and Needleman (1988) coalescence occurs when localized deformation takes place in the ligaments between the voids, leading to unloading in a significant part of the cell, as well as the onset of a uniaxial straining mode. In the present analyses we define that the onset of coalescence takes place if the maximum value of the effective plastic strain rate along the top of the cell is below $1 \%$ of the reference plastic strain rate, $\dot{\varepsilon}_{0}$, at a residual strain of $0.4 \%$ (twice the strain at which the yield point is defined). The coalescence regime is found by sweeping through increasing values of $\rho$, and the lowest value of $\rho$ that fulfills the criterion is defined as the first point on the yield surface belonging to the coalescence regime. We have found that this criterion is robust as well as simple to check, while it remains in good agreement with definitions in terms of localization and the onset of the uniaxial straining mode. For the conventional yield surfaces the slope near the mean stress axis is in good agreement with the coalescence criterion of Thomason (1985) (see also Besson, 2010). 
For $f_{0}=0.04$ the largest length scale does not exhibit coalescence on any part of the yield surface, while for $f_{0}=0.08$ the two larger length scales do not exhibit coalescence. Figure 5 also shows that the yield surfaces intersect the mean stress axis at an increasing angle with decreasing void size (i.e. increasing $L_{D} / R_{v}$ ).

We will now explore how a simple transformation of conventional yield surfaces may be used to fit the size-dependent yield surfaces. For the conventional material the results obtained may be expressed by the following general form of a yield function

$$
F=F\left(\sigma_{e}, f, \sigma_{m}, \sigma_{y}\right)
$$

For zero mean stress Figure 5 shows that the yield surfaces intersect the von Mises stress axis at higher values when the porosity decreases.

The following two observations for the size-dependent yield surfaces are made

1. Yield surfaces for size-dependent material behavior $\left(L_{D}>0\right)$ intersect the von Mises stress axis at increasing values as the size of the voids decreases.

2. Size-dependent yield surfaces are stretched significantly along the mean stress axis.

These two observations lead us to suggest that the yield surfaces for sizedependent material behavior may be modeled by that of a conventional material with

1. A smaller void volume fraction.

2. Less mean stress sensitivity.

Following this hypothesis a size-dependent yield surface may be generalized from the conventional yield surface (20) according to the transformation

$$
F=F\left(\sigma_{e}, Q_{1} f, Q_{2} \sigma_{m}, \sigma_{y}\right)
$$

with $Q_{1} \leq 1$ and $Q_{2} \leq 1$ depending on the size of the voids. In principle the values of $Q_{1}$ and $Q_{2}$ may for the present problem also depend on the initial void volume fraction. However, we will show later that, to a very good approximation, the present unit cell analyses suggest that the transformation values depend only on void size. 
Initially we test the hypothesis for $f_{0}=0.04$ by comparing yield surfaces for the conventional material with the corresponding size-dependent material with $L_{D} / R_{v}=0.40$. Results are presented in Figure 6 . The figure shows the conventional results (dotted curve) and size-dependent results with $L_{D} / R_{v}=0.40$ (solid curve). Furthermore two yield surfaces are included in order to fit the size-dependent yield surface through a transformation of conventional yield surface with 1) a smaller void volume fraction and 2) less mean stress sensitivity (dashed curves). Both of the transformed conyentional yield surfaces have $Q_{1}=0.75$ (corresponding the the smaller void volume fraction 0.03), and they are observed to give good agreement with the size-dependent yield surface on the von Mises stress axis, where the mean stress is zero. While one of the transformed yield surfaces maintains $Q_{2}=1$, the other having $Q_{2}=0.67$ fits the size-dependent yield surface well by stretching it appropriately along the mean stress axis.

In order to accurately determine $Q_{1}$ for a given void size specified by $L_{D} / R_{v}$ we propose the following procedure: A sequence of analyses determining the yield point at zero mean stress, (denoted by $S$ ) for a range of values of $f_{0}$ are carried out for both the conventional material $\left(S_{\text {conv. }}\right)$ and the size-dependent material $\left(S_{S G P}\right)$. The results may be presented as shown in Figure 7 for the void size given by $L_{D} / R_{v}=0.40$. For the relevant value of $f_{0}$ for the size-dependent material (in the example from Figure 6 this value is $\left.f_{0}=0.04\right)$ the yield stress is found. Then the transformation parameter $Q_{1}$ may be determined as the factor that $f_{0}=0.04$ should be scaled by in order to yield a porosity for a conventional material with the same yield stress. In the example of Figure 7 that relates to the results in Figure 6, we determine that $Q_{1} \approx 0.03 / 0.04=0.75$.

In principle the procedure for determining $Q_{1}$ could depend on porosity, $f_{0}$, and this dependence will now be investigated. Figure 8 shows results for $Q_{1}$ as a function of $f_{0}$ based on the procedure proposed in relation to Figure 7 . Results are presented for a number of different void sizes, and it is seen that for a given void size, the transformation parameter $Q_{1}$ is largely independent of $f_{0}$. For each value of void size we define $Q_{1}$ as the average value in the porosity range $f_{0} \in[0.01 ; 0.03]$.

Figure 9 shows the value of $Q_{1}$ and $Q_{2}$ as they are determined to depend on void size. The markers show the numerical results obtained, and the curves show fits to the numerical results. For large void sizes $\left(L_{D} / R_{v} \rightarrow 0\right)$ the transformation parameters approach unity. For increasing void sizes they are observed to be monotonically decreasing. In the limit of vanishing void 
size $\left(R_{v} \rightarrow 0\right)$ a lower bound for $Q_{1}$ has been found as

$$
\lim _{R_{v} \rightarrow 0} Q_{1} \approx 0.636
$$

The existence of a lower bound of $Q_{1}$ is related to the fact that as strain gradient strengthening becomes dominant, the deformation field approaches homogeneous deformation, which according to limit load analysis is consistent with the yield condition $\sigma_{e} / \sigma_{y}=(1-f)$. At zero mean stress only $Q_{1}$ has an effect on the transformation of the yield surface. Hence, $Q_{1}$ can not be so small that the yield surface of a conventional material with volume fraction $Q_{1} f$ exceeds the limit $\sigma_{e} / \sigma_{y}=(1-f)$. The lower bound for $Q_{2}$ is expected to be zero.

The transformation parameters have been determined based on numerical results in the range of porosities from 0.01 to 0,03 . In Figure 10 conventional (dotted curves) and size-dependent (solid curves) yield surfaces are shown together with the transformed yield surfaces proposed (dashed curves) for three different porosities and three difference void sizes. The three columns show results for $L_{D} / R_{v}=0.10,0.20$ and 0.40 , respectively, and the three rows show results for $f_{0}=0.01,0.04$ and 0.08 , respectively. Although the numerical fits are found for porøsity values around $f_{0}=0.02$, the transformation procedure is seen to give very good results both for smaller void volume fractions and very large void volume fractions.

\section{Discussion}

A finite strain generalization of the strain gradient plasticity theory by Gudmundson (2004), which was reformulated mathematically by Fleck and Willis (2009b) has been proposed. In accordance with previous studies it is shown how size-effects expand the yield surface and suppress void growth on the micron scale. Monchiet and Bonnet (2013) used limit load analysis to show that the Gurson yield surface could be enriched to capture sizedependence by introducing a size-dependence in the mean stress in the yield function. Here we propose a simple transformation of conventional yield surfaces for porous metals in order to account for micron scale size-dependence. The transformation includes two parameters $Q_{1}$ and $Q_{2}$ that depend on void size, and which have the effect of scaling the void volume fraction dependence and mean stress dependence of the yield surface, respectively. The transformation parameters are determined as a function of void size, and they are 
shown to be largely independent of void volume fractions. In Figure 9 the markers show the numerically determined values of $Q_{1}$ and $Q_{2}$ along with curve fits following the expressions.

$$
\begin{aligned}
Q_{1} & \approx \frac{0.364}{1+1.8\left(\frac{L_{D}}{R_{v}}\right)+10\left(\frac{L_{D}}{R_{v}}\right)^{2}}+0.636 \\
Q_{2} & \approx \frac{1}{1+1.8\left(\frac{L_{D}}{R_{v}}\right)^{3 / 2}}
\end{aligned}
$$

As an approximation the method proposed here could be applied with a previously known yield surface for a conventional material. A frequently used example is the Gurson model with the yield surface specified by

$$
F=\frac{\sigma_{e}^{2}}{\sigma_{y}^{2}}+2 q_{1} f \cosh \left(\frac{3 q_{2} \sigma_{m}}{2 \sigma_{y}}\right)-1-\left(q_{1} f\right)^{2}=0
$$

Here, the parameters $q_{1}$ and $q_{2}$ were proposed by Tvergaard (1981) to improve the accuracy of predictions for the conventional material. Sometimes the parameter values are taken to be $q_{1}=1.5$ and $q_{1}=1$, but some authors use slightly different values. Now, to obtain the yield surface for strain gradient plasticity, using the results of Section 5 , one would use the appropriate values of $Q_{1}$ and $Q_{2}$ for the relevant value of $L_{D} / R_{v}$, and then use the yield condition (25) with $f$ replaced by $Q_{1} f$ and with $\sigma_{m}$ replaced by $Q_{2} \sigma_{m}$. This means that the yield surface used for the strain gradient plasticity material is the standard Gurson expression (25), with $q_{1}$ replaced by $Q_{1} q_{1}$ and $q_{2}$ replaced by $Q_{2} q_{2}$. For the usual value $q_{1}=1.5$ the product $Q_{1} q_{1}$ would be very close to unity, which in principle is an upper bound for the coefficient on $f$ in the modified Gurson model.

The proposed procedure can also be used for other yield functions for porous metals, such as that found by Shima and Oyane (1976) for powder compacted metals. Here a quadratic expression in terms of the Mises stress and the mean stress was used, with the coefficients fitted to experiments. If this expression is used for the conventional material, the yield condition for the strain gradient plasticity material would be obtained when $f$ is replaced by $Q_{1} f$ and $\sigma_{m}$ is replaced by $Q_{2} \sigma_{m}$.

We conjecture that the proposed procedure may be used with good approximation for any isotropic yield surface for porous metals that includes 
explicit dependence on porosity and mean stress. Obviously more numerical and experimental evidence of this should be gathered to support or contradict this.

\section{Acknowledgement}

This research was financially supported by Danish Council for Independent Research through the research project "Advanced Damage Models with InTrinsic Size Effects" (Grant no: DFF-7017-00121). Discussions with Associate Professor Kim Lau Nielsen on the finite strain framework are highly acknowledged.

\section{References}

Benzerga, A. A., Leblond, J.-B., 2010. Ductile fracture by void growth to coalescence. Advances in Applied Mechanics 44, 169-305.

Benzerga, A. A., Leblond, J.-B., Needleman, A., Tvergaard, V., 2016. Ductile failure modeling. International Journal of Fracture 201, 29-80.

Besson, J., 2010. Continuum models of ductile fracture: A review. International Journal of Damage Mechanics 19, 3-52.

Borg, U., Niordson, C. F., Kysar, J. W., 2008. Size effects on void growth in single crystals with distributed voids. International Journal of Plasticity $24(4), 688-701$

Brach, S., Dormieux, L., Kondo, D., Vairo, G., 2017. Strength properties of nanoporous materials: A 3-layered based non-linear homogenization approach with interface effects. International Journal Engineering Science $15,28-42$.

Dormieux,L., Kondo, D., 2010. An extension of Gurson model incorporating interface stresses effects. International Journal of Engineering Science 48, $575-581$.

Fleck, N. A., Hutchinson, J. W., 1997. Strain gradient plasticity. In: Hutchinson, J. W., Wu, T. Y. (Eds.), Advances in Applied Mechanics. Vol. 33. Academic Press, pp. 295-361. 
Fleck, N. A., Hutchinson, J. W., 2001. A reformulation of strain gradient plasticity. Journal of the Mechanics and Physics of Solids 49, 2245-2271.

Fleck, N. A., Muller, G. M., Ashby, M. F., Hutchinson, J. W., 1994. Strain gradient plasticity: Theory and experiment. Acta Metallurgica et Materialia $42(2), 475-487$.

Fleck, N. A., Willis, J. R., 2009a. A mathematical basis for strain-gradient plasticity theory - Part I: Scalar plastic multiplier. Journal of the Mechanics and Physics of Solids 57, 161-177.

Fleck, N. A., Willis, J. R., 2009b. A mathematical basis for strain-gradient plasticity theory - Part II: Tensorial plastic multiplier. Journal of the Mechanics and Physics of Solids 57, 1045-1057.

Garrison, W. R., Moody, N. R., 1987. Ductile fracture. Journal of Physics an Chemistry of Solids 48, 1035-1074.

Gudmundson, P., 2004. A unified treatment of strain gradient plasticity. Journal of the Mechanics and Physics of Solids 52, 1379-1406.

Gurson, A. L., 1977. Continuum theory of ductile rupture by void nucleation and growth: Part I. Yield criteria and flow rules for porous ductile media. Journal of Engineering Materials and Technology 99, 2-15.

Haque, M. A., Saif, M. T. A., 2003. Strain gradient effect in nanoscale thin films. Acta Materialia 51)(11), 3053-3061.

Huang, Y., Gao, H., Nix, W. D., Hutchinson, J. W., 2000. Mechanism-based strain gradient plasticity-II. analysis. Journal of the Mechanics and Physics of Solids 48, 99-128.

Koplik, J., Needleman, A., 1988. Void growth and coalescence in porous plastic solids. International Journal of Solids and Structures 24, 835-853.

Li, Z., Huang, M., Cheng, W., 2003. Scale-dependent plasticity potential of porous materials and void growth. International Journal of Solids and Structures 40, 3935-3954.

Li, Z., Steinmann, P., 2006. RVE-based studies on the coupled effects of void size and void shape on yield behavior and void growth at micron scales. International Journal of Plasticity 22, 1195-1216. 
Ling, C., Forest, S., Besson, J., Tanguy, B., Latourte, F., 2018. A reduced micromorphic single crystal plasticity model at finite deformations. application to strain localization and void growth in ductile metals. International Journal of Solids and Structures 134, 43-69.

Ma, Q., Clarke, D. R., 1995. Size dependent hardness of silver single crystals. Journal of Materials Research 10, 853-863.

McClintock, F. A., 1968. A criterion for ductile fracture by the growth of holes. Journal of Applied Mechanics 35, 363-371.

McMeeking, R. M., Rice, J. R., 1975. Finite-element formulations for problems of large elastic-plastic deformation. International Journal of Solids and Structures 11, 601-616.

Monchiet, V., Bonnet, G., 2013. A Gurson-type model accounting for void size effects. International Journal of Solids and Structures 50, 320-327.

Monchiet, V., Kondo, D., 2013. Combined voids size and shape effects on the macroscopic criterion of ductíle nanoporous materials. International Journal of Plasticity 43, 20-41.

Morin, L., Kondo, D., Leblond, J.-B., 2015. Numerical assessment, implementation and application of an extended Gurson model accounting for void-size effects. European Journal of Mechanics A/Solids 51, 183-192.

Nielsen, K. L., Niordson, C. F., 2014. A numerical basis for strain-gradient plasticity theory: Rate-independent and rate-dependent formulations. Journal of the Mechanics and Physics of Solids 63, 113-127.

Niordson, C, F., 2008. Void growth to coalescence in a non-local material. European Journal of Mechanics A/Solids 27, 222-233.

Niordson, C. F., Hutchinson, J. W., 2011. Basic strain gradient plasticity theories with application to constrained film deformation. Journal of Mechanics of Materials and Structures 6, 395-416.

Niordson, C. F., Tvergaard, V., 2006. Size-effects on cavitation instabilities. Journal of Applied Mechanics 73, 246-253.

Niordson, C. F., Tvergaard, V., 2007. Size-effects in porous metals. Modelling and Simulation in Materials Science and Engineering 15, 51-60. 
Rice, J. R., Tracey, D. M., 1969. On the ductile enlargement of voids in triaxial stress fields. Journal of the Mechanics and Physics of Solids 17, 201-217.

Stelmashenko, N. A., Walls, M. G., Brown, L. M., Milman, Y. V., 1993. Microindentations on $\mathrm{W}$ and Mo oriented single crystals: An SEM study. Acta Metallurgica et Materialia 41 (10), 2855-2865.

Stölken, J. S., Evans, A. G., 1998. A microbend test method for measuring the plasticity length scale. Acta Materialia 46 (14), 5109-5115.

Swadener, J. G., George, E. P., Pharr, G. M., 2002. The correlation of the indentation size effect measured with indenters of various shapes. Journal of the Mechanics and Physics of Solids 50, 681-694.

Thomason, P. F., 1985. A three-dimensional model for ductile fracture by the growth and coalescence of microvoids. Acta Metallurgica 33 (6), 10871095.

Tvergaard, V., 1981. Influence if voids on shear band instabilities under plane strain conditions. International Journal of Fracture 17, 389-407.

Tvergaard, V., 1990. Material failure by void growth to coalescence. In: Hutchinson, J. W., Wu, T. Y. (Eds.), Advances in Applied Mechanics. Vol. 27. Academic Press, pp. 83-151.

Wen, J., Huang, Y., Hwang, K. C., Liu, C., Li, M., 2005. The modified Gurson model accounting for the void size effect. International Journal of Plasticity 21, 381-395.

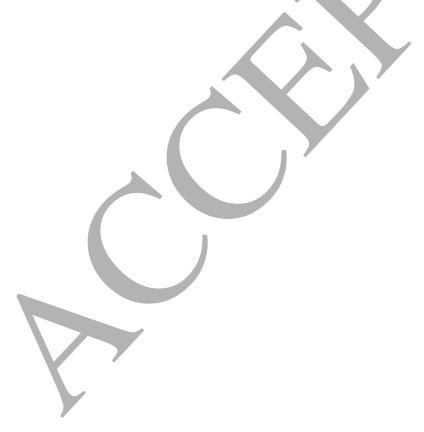




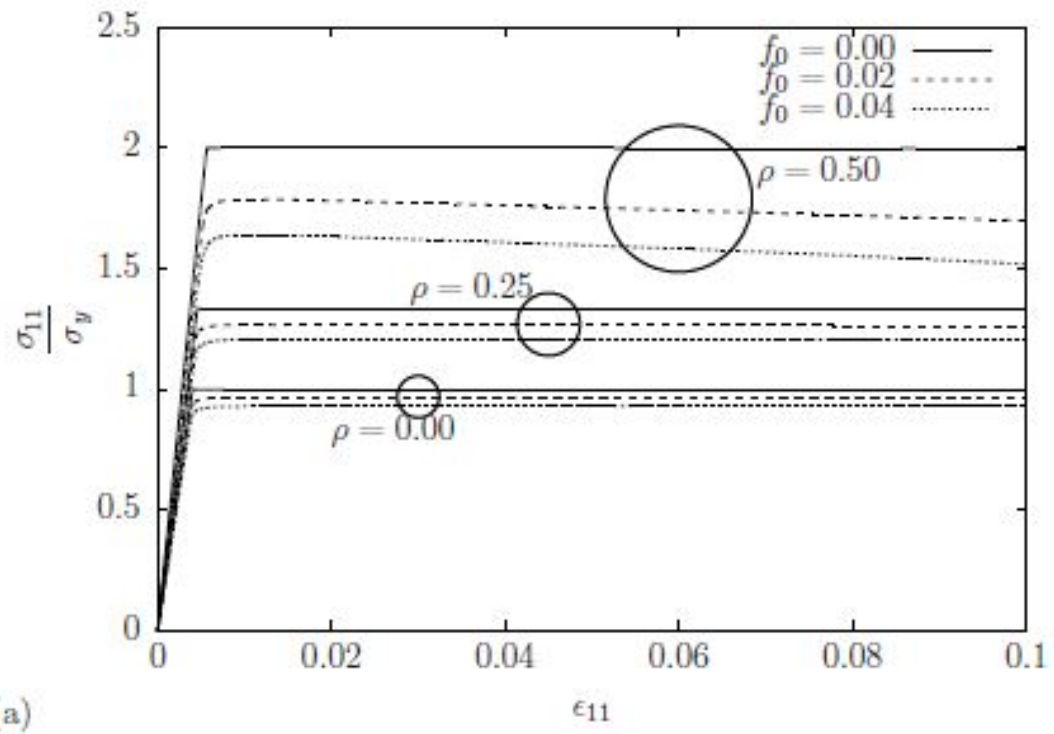

(a)

$\epsilon_{11}$

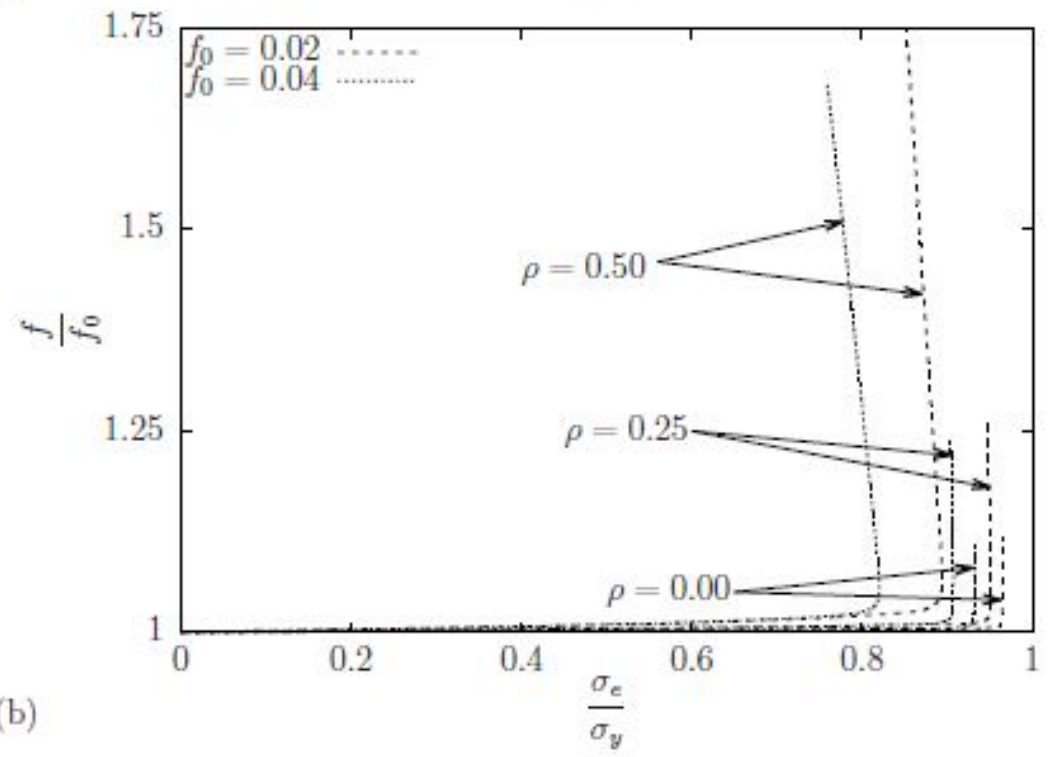

Figure 2: (a) Conventional response curves and (b) void growth curves are shown for three initial void volume fractions, $f_{0}=0,0.02,0.04$ and three different stress ratios, $\rho=0,0.25,0.50$. 


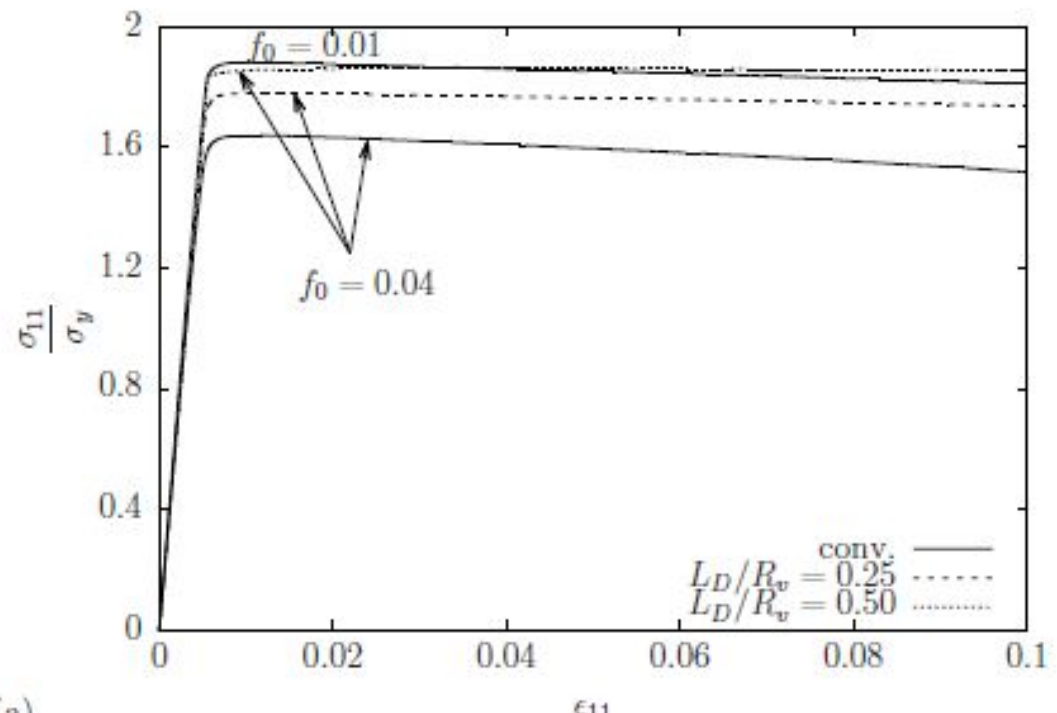

(a)

$\epsilon_{11}$

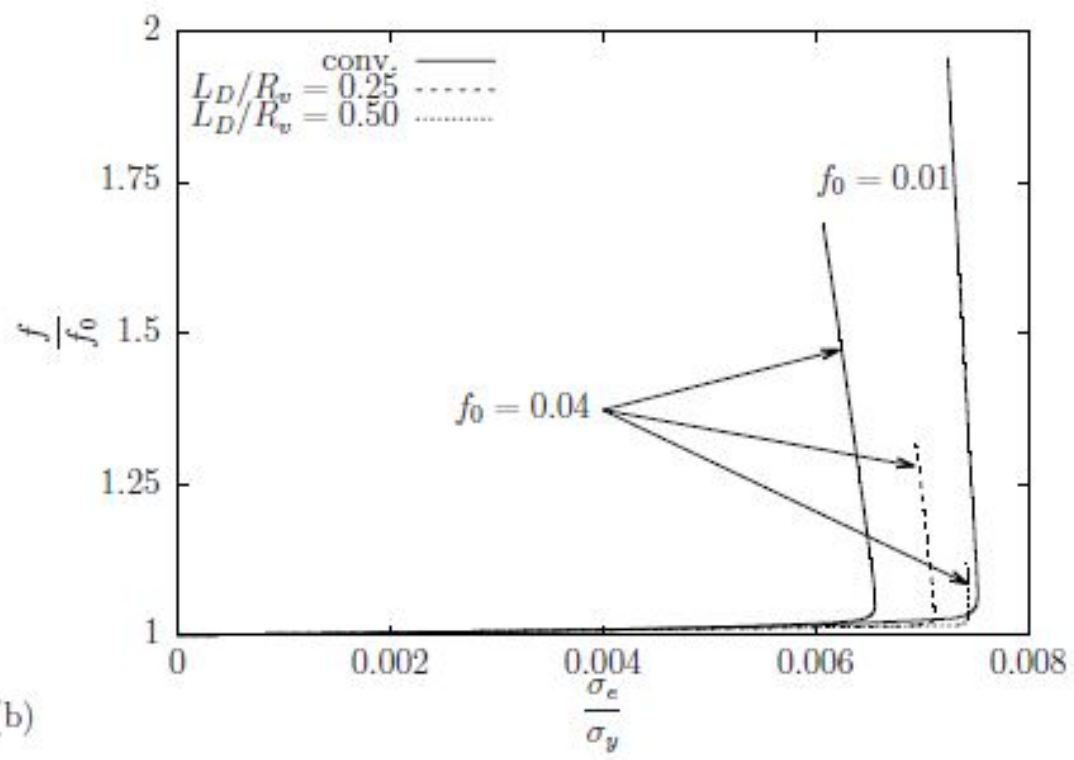

Figure 3: For a stress ratio of $\rho=0.50$ the figure shows (a) response curves and (b) void growth curves for two initial void volume fractions, $f_{0}=0.01,0.04$. Results are shown for conventional materials. Furthermore, results are included for the size-dependent material behavior $\left(L_{D} / R_{v}=0.25,0.50\right)$ for the larger porosity $f_{0}=0.04$. 


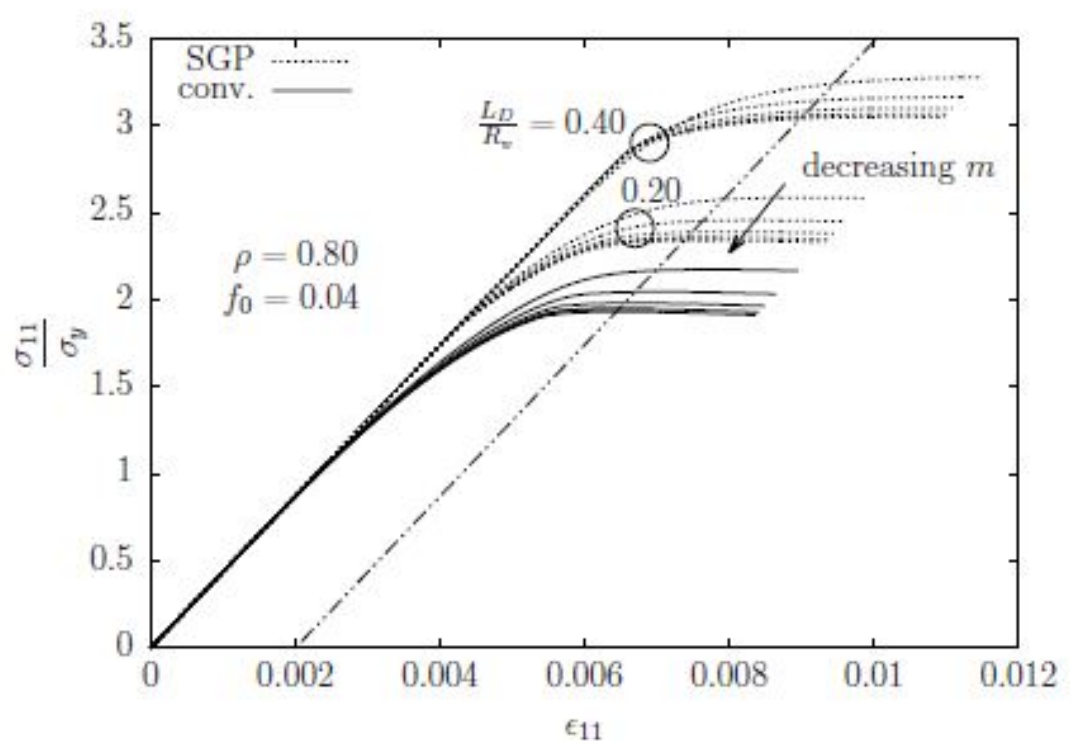

Figure 4: The yield point is determined at $0.2 \%$ plastic strain as illustrated for $f_{0}=0.04$, $\rho=0.80$ and the three values of material length parameter $L_{D} / R_{v}=0,0.20,0.40$. Results are shown for five values of the rate hardening exponent, $m=0.005,0.01,0.02,0.04,0.08$.

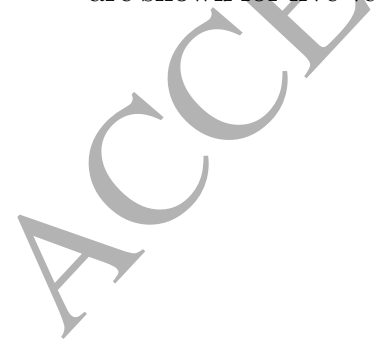




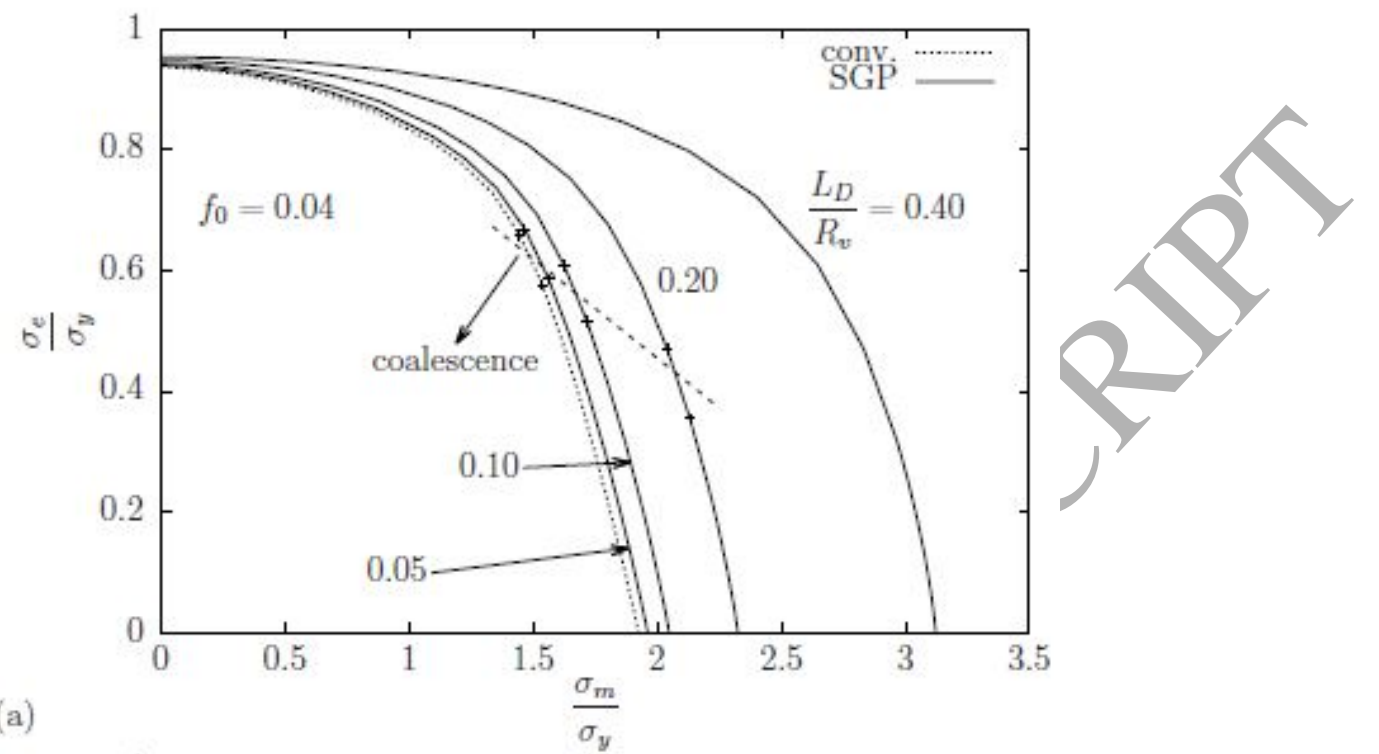

(a)

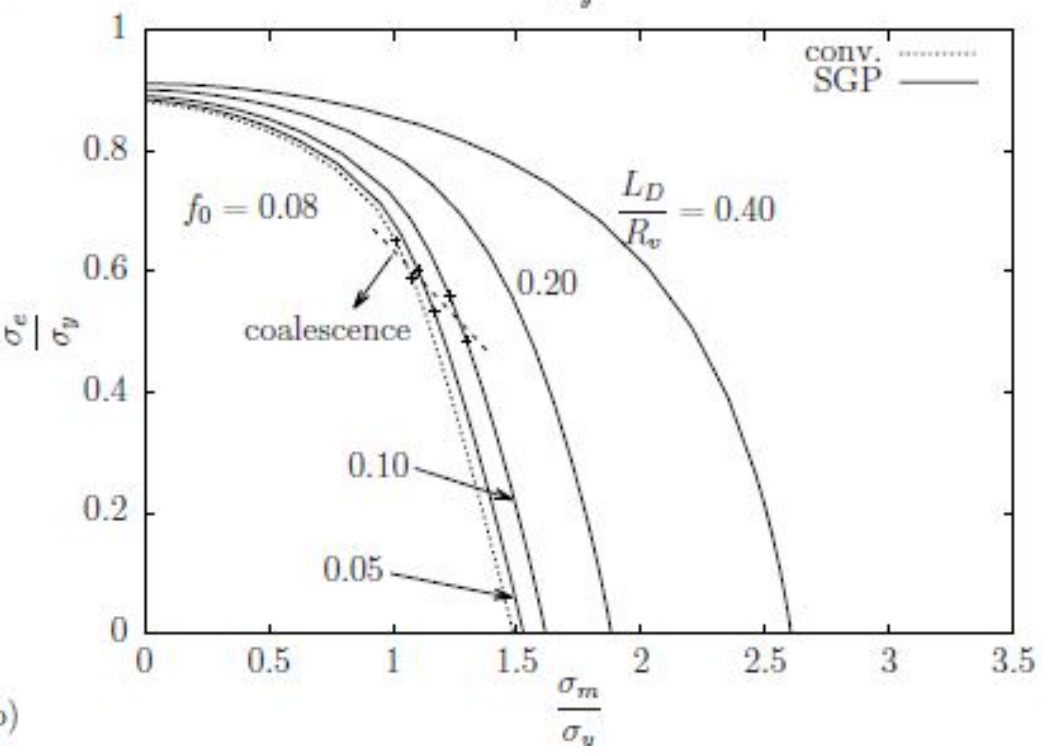

Figure 5: Yield surfaces for the porosities (a) $f_{0}=0.04$ and (b) $f_{0}=0.08$. The dotted curves show the yield surfaces for conventional material behavior, and the solid curves show size-dependent results for different values of the ratio of material length parameter to initial void size, $L_{D} / R_{v}$. The dashed lines indicate the boundaries between the regimes of void growth and void coalescence. The two markers on each yield surface indicate the finite element analyses carried out, which are closest to the boundary. 

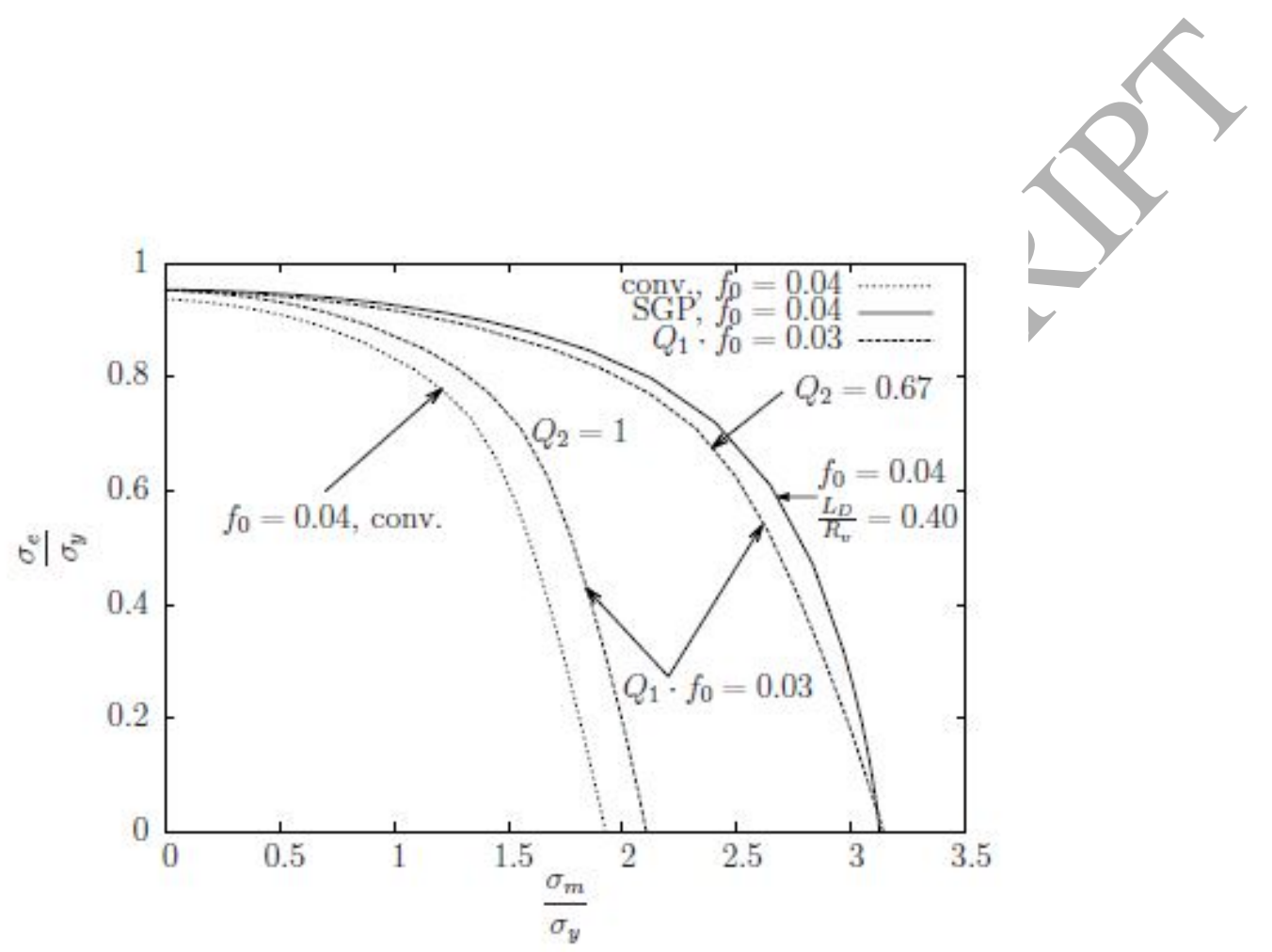

Figure 6: Yield surfaces for $f_{\emptyset}=0.04$. The figure shows the conventional results (dotted curve) and size-dependent results with $L_{D} / R_{v}=0.40$ (solid curve). Furthermore two yield surfaces are included in order to fit the size-dependent yield surface through a transformation of conventional yield surface with 1) a smaller void volume fraction and 2) less mean stress sensitivity (dashed curves). Both of the transformed conventional yield surfaces have $Q_{1}=0.75$ (corresponding the the smaller void volume fraction 0.03 ). While one of the transformed yield surfaces maintains $Q_{2}=1$, the other having $Q_{2}=0.67$ fits the size-dependent yield surface well. 


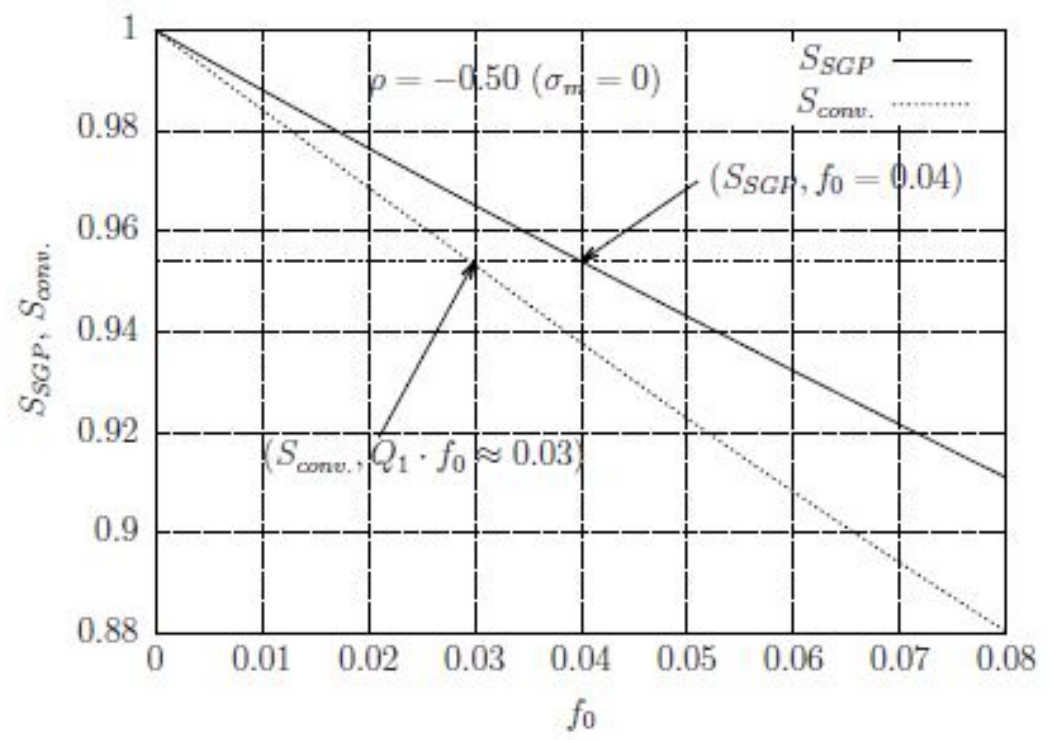

Figure 7: The figure shows the yield stress at zero mean stress $(\rho=-0.5)$ as a function of porosity for the size-dependent material as well as for a conventional material. The procedure to obtain $Q_{1}$ is illustrated for $f_{0}=0.04$ and $L_{D} / R_{v}=0.40$. According to the intersections we determine $Q_{1}$ as follows: $Q_{1}\left(L_{D} / R_{v}=0.40\right) \approx 0.03 / 0.04$. 


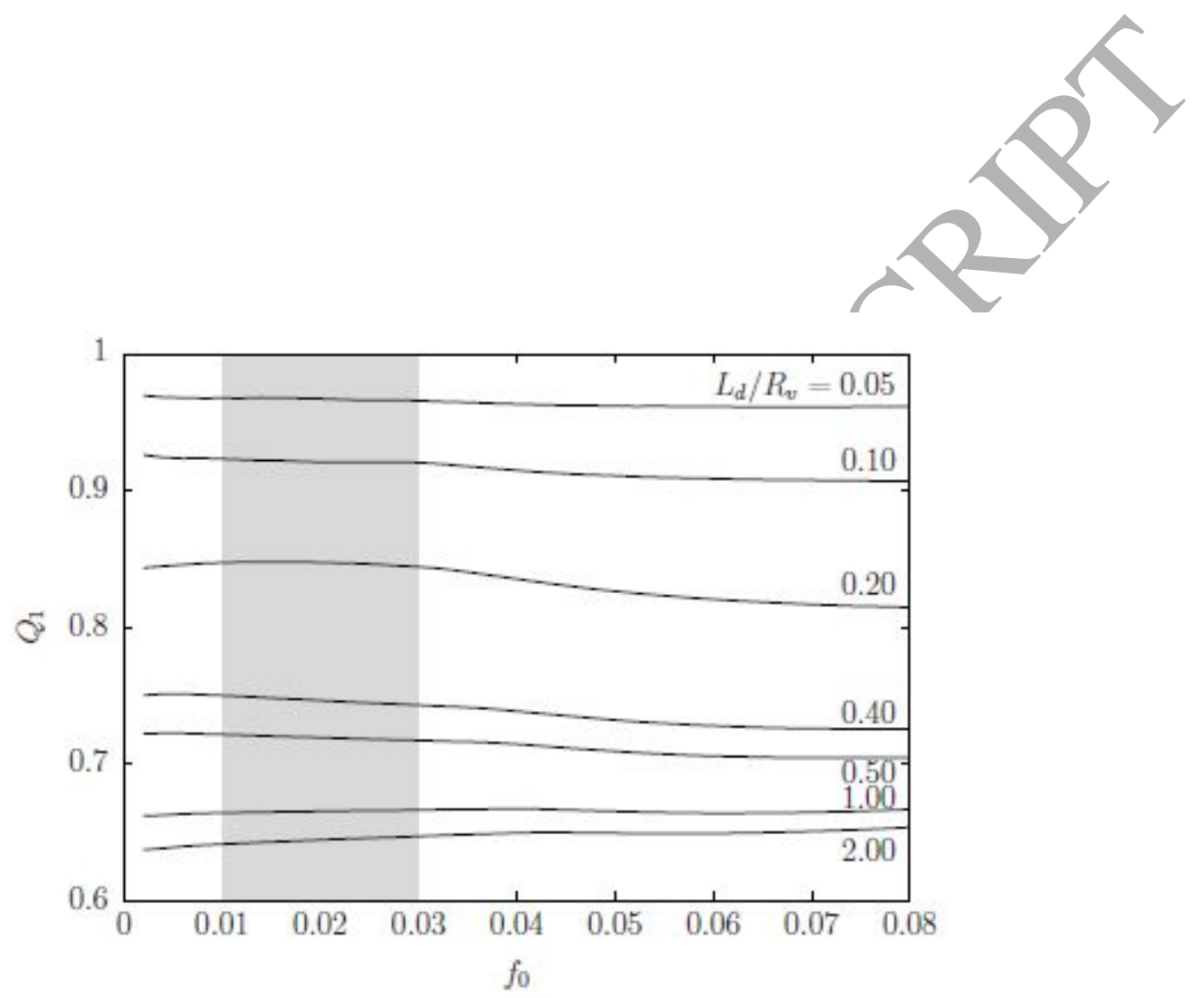

Figure 8: For each individual value of $L_{D} / R_{v}$, the value of $Q_{1}$ is averaged in the interval $f_{0} \in[0.01 ; 0.03]$.

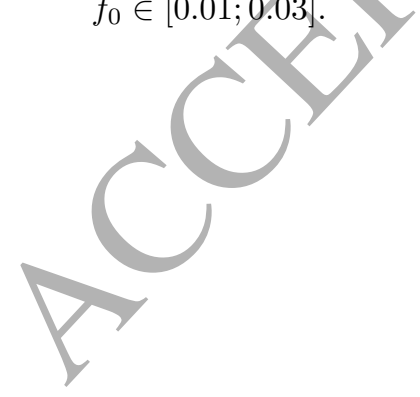




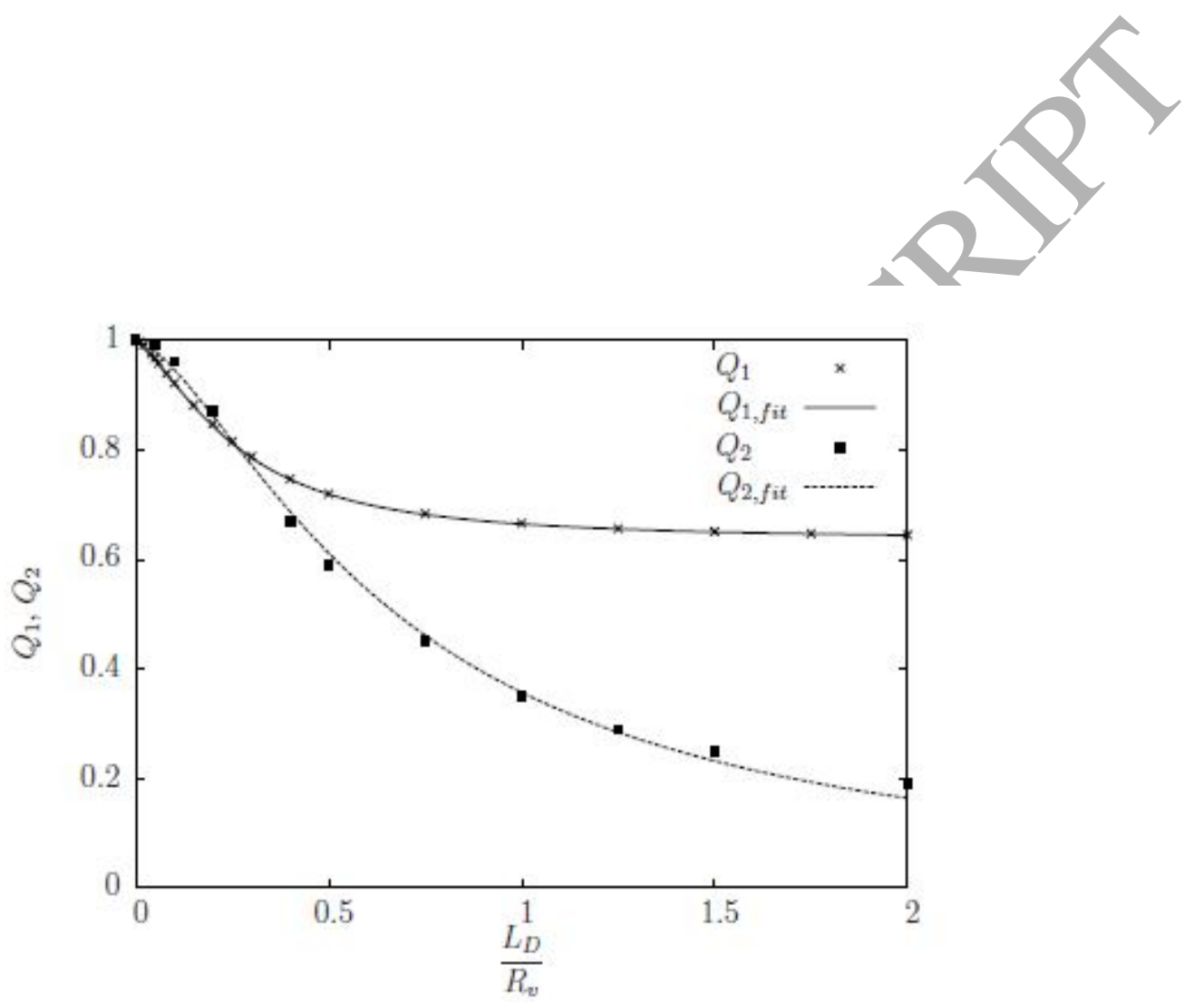

Figure 9: Transformation parameters $Q_{1}$ and $Q_{2}$ as a function of inverse porosity size. The markers show the numerical results obtained, and the lines show proposed fits to the numerical results.)

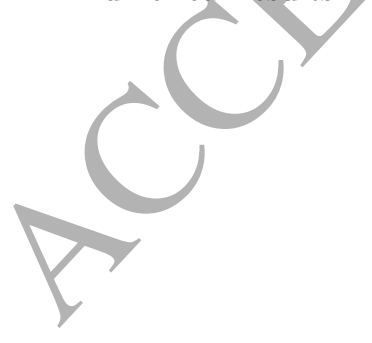




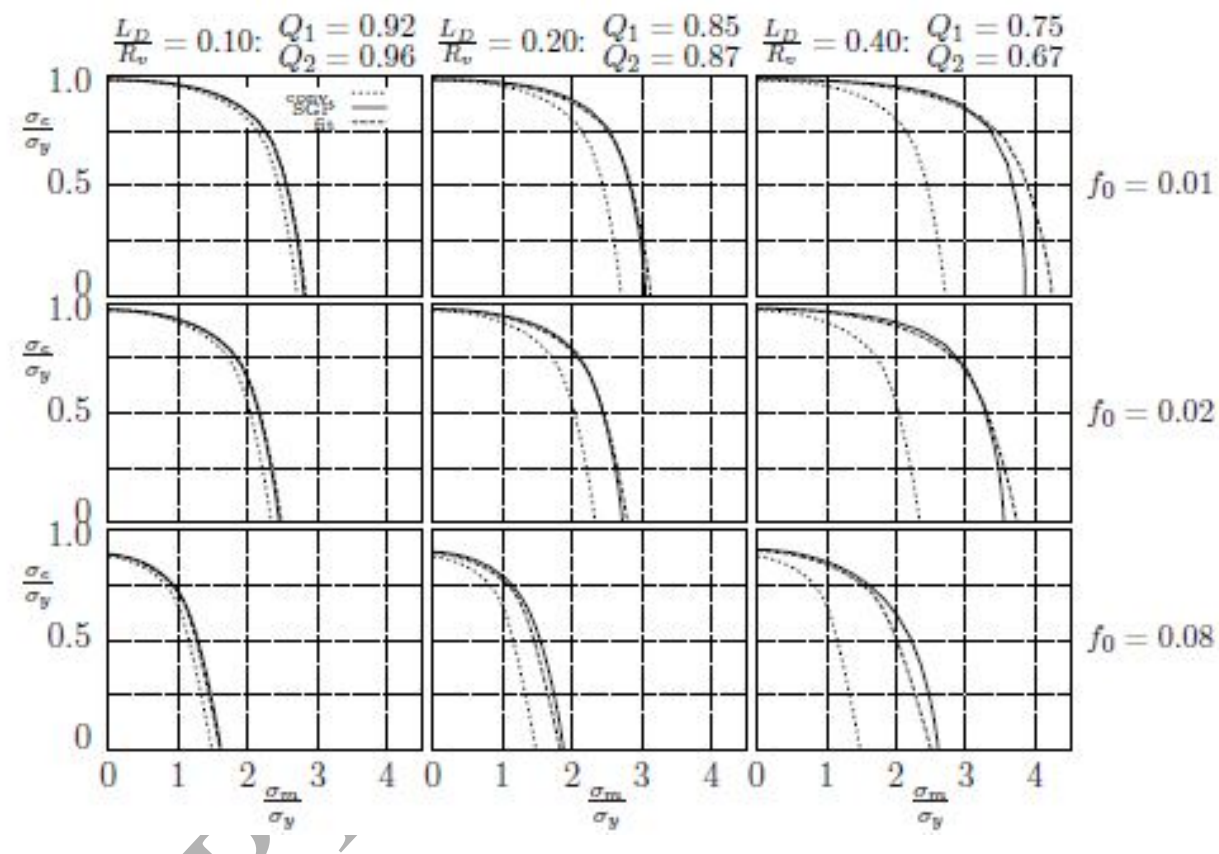

Figure 10: Conventional (dotted curves) and size-dependent (solid curves) yield surfaces are shown together with the transformed yield surfaces proposed (dashed curves) for three porosities $\left(f_{0}=0.01,0.04\right.$ and 0.08$)$ and three void sizes $\left(L_{D} / R_{v}=0.10,0.20\right.$ and 0.40$)$. 